\title{
Gallant geese, fearful flocks? Flock size and heterospecifics alter the escape behaviour of an invasive goose
}

\author{
Evelien Deboelpaep", Pieter-Jan Keleman, \\ Bram Vanschoenwinkel \& Nico Koedam \\ Vrije Universiteit Brussel, Department of Biology, Ecology \& Biodiversity Section, \\ Pleinlaan 2, 1050 Brussels, Belgium. \\ *Corresponding author: evelien.deboelpaep@vub.be
}

\begin{abstract}
While escape responses are shown to differ in areas with varying levels of human disturbance, it is not known to what extent these reactions depend on the composition of local species assemblages. We investigated variation in three flight response metrics for the invasive Canada Goose (Branta canadensis) in Belgium in three locations with different human accessibility. Results indicate that heterospecific birds and flock size affected flight initiation distances of the Canada Goose, but that these effects are location-specific. Escape responses were most pronounced in the nature reserve with the lowest human accessibility, and highly reduced in the recreational park. This study illustrates that, when buffer zones are being developed, generalising escape behaviour of birds may lead to potentially dangerous overestimations of their tolerance to human disturbance.
\end{abstract}

Keywords. Branta canadensis, flight initiation distance, flock composition, human disturbance, nature reserve.

Deboelpaep E., Keleman P.-J., Vanschoenwinkel B. \& Koedam N. (2018). Gallant geese, fearful flocks? Flock size and heterospecifics alter the escape behaviour of an invasive goose. Belgian Journal of Zoology 148 (2): 135-147. https://doi.org/10.26496/bjz.2018.23

\section{Introduction}

In conservation practice, nature and recreational values must be balanced in a context of increasing habitat degradation and a growing interest for ecotourism. When a strict separation between nature and human activities is no longer an option, the presence of people unavoidably interferes with the daily activities of birdlife (BEALE \& MONAGHAN 2004; COLLINS-KREINER et al. 2013; ARLETTAZ et al. 2015; HAGY et al. 2017). Some birds, such as Branta canadensis (Linnaeus, 1758), can even be drawn to urban areas to avoid higher hunting pressure and thermoregulation costs associated with rural areas, increasing the potential for human-wildlife conflicts (DORAK et al. 2017).

To mitigate disturbance, one of the most commonly used techniques is to restrict human access in buffer zones (SCHLACHER et al. 2013a). Buffer distances can be quantified by the 'Flight Initiation Distance' (FID), the distance between the animal and the source of disturbance at which the animal takes flight (LIN et al. 2012). Taking flight is a distinct behaviour that requires a substantial energetic investment and is directly associated with habitat abandonment (GLOVER et al. 2011; GUAY et al. 2013; SCHLACHER 
et al. 2013b). Flight initiation distances are therefore a frequently-used indicator for the tolerance level of animals to disturbance (GENDALL et al. 2015).

Flock size is one of the major variables influencing escape behaviour in waterbirds, with evidence of both positive and negative effects of flock size on FIDs (LAURSEN et al. 2005; KAHLERT 2006; WANG et al. 2011; TÄTTE et al. 2018). Almost paradoxically, larger flocks display more pronounced escape responses, even though gregarious lifestyles stem from a "safety in numbers" mechanism that evolved as a protection strategy from predators, whereby the risk of being attacked is diluted for many individuals (LEHTONEN \& JAATINEN 2016). This protection strategy makes sense when safety is interpreted as an increased predator avoidance potential (LAURSEN et al. 2005; 2016). Because of a general tendency to take flight quickly after detecting a threat (SAMIA et al. 2013) and a higher probability of larger flocks detecting threats, the vigilant individuals can initiate an early flight reaction that cascades through the entire flock as a reflex (KAHLERT 2006; BEAUCHAMP, 2012; LEHTONEN \& JAATINEN 2016; BOUJJAMILJOUR et al. 2017). While others remain vigilant, individuals can reduce their own scanning time and allocate more time to other activities (WANG et al. 2011). On the contrary, the distance birds fly when disturbed, and hence the duration of the escape response, was found to be shorter for larger flocks of Greater Snow Geese Anser caerulescens atlanticus (Kennard, 1927) (BÉCHET et al. 2004). This observation was attributed to a larger proportion of animals in the flock that was not necessarily aware of the initial cause for fleeing and of whether the threat is real or only perceived (BÉCHET et al. 2004). In Mallard Anas platyrhynchos (Linnaeus, 1758), there appeared to be no effect of flock size on the distance flown after being approached by walking observers, both when the disturbance was followed by a shooting signal and when not (DOOLEY et al. 2010).

For species that occur in mixed-species flocks during a considerable part of the year, such as many waterbird species do, various interactions between flock members may have an important effect on vigilance and antipredator responses. In most studies on escape behaviour, however, species are investigated in isolation or without specifically addressing flock composition (LAURSEN et al. 2005; CHATWIN et al. 2013; VINCZE et al. 2016). The principles underlying flock formation, such as safety and ecological similarity (SRIDHAR \& SHANKER 2014; LEHTONEN \& JAATINEN, 2016), might also be related to characteristics that determine sensitivity to disturbance and the cascading of flight reflexes.

It is known that populations colonising urbanised environments often lose their wariness of humans faster than their rural conspecifics (SOL et al. 2013), as evidenced in House Sparrows Passer domesticus (Linnaeus, 1758) (VINCZE et al. 2016) and Eurasian Red Squirrels Sciurus vulgaris (Linnaeus, 1758) (UCHIDA et al. 2016). More specifically, exotic species that become invasive beyond their natural ranges often owe their ecological success to more flexible and bolder behavioural traits (LODGE 1993; SOL et al. 2002; COTE et al. 2010; CHAPPLE et al. 2012). However, it remains unknown whether such bold species still show geographic variation in their escape strategies, under different population densities and in the presence of different sets of associated species. This information would be useful, not just to better understand whether determinants of escape behaviour can be generalised across contexts, but also to support management actions such as nature reserve design and more effective control programs in the case of pest species.

In this study, we focus on the Canada Goose as an invasive exotic in Belgium. Its history as a captive ornamental species may have induced habituation to 'harmless' humans (GEFFROY et al. 2015). However, to control increasing Canada Geese populations, targeted hunting was permitted from 1998 onwards. More intensive culling activities were established the following decade, including an adapted hunting scheme, egg puncturing and euthanasing moulting geese flocks (VAN DAELE et al. 2012). Such invasive measures might have induced more pronounced flight reactions (BEJDER et al. 2009).

We examine the flexibility of the flight behaviour of Canada Geese as a function of flock composition by experimentally inducing escape responses. We hypothesise that escape responses increase when less disturbance-tolerant waterbird species are present and when flock size increases. Even though feral 
Canada Goose populations in Belgium originated from domestic animals, we expect that variations in human access to habitats and culling activities should have stimulated local differences in escape behaviour. By comparing three escape response metrics, i.e., two types of flight initiation distances and the total duration of the flight reaction, we distinguish different phases that have different biological implications.

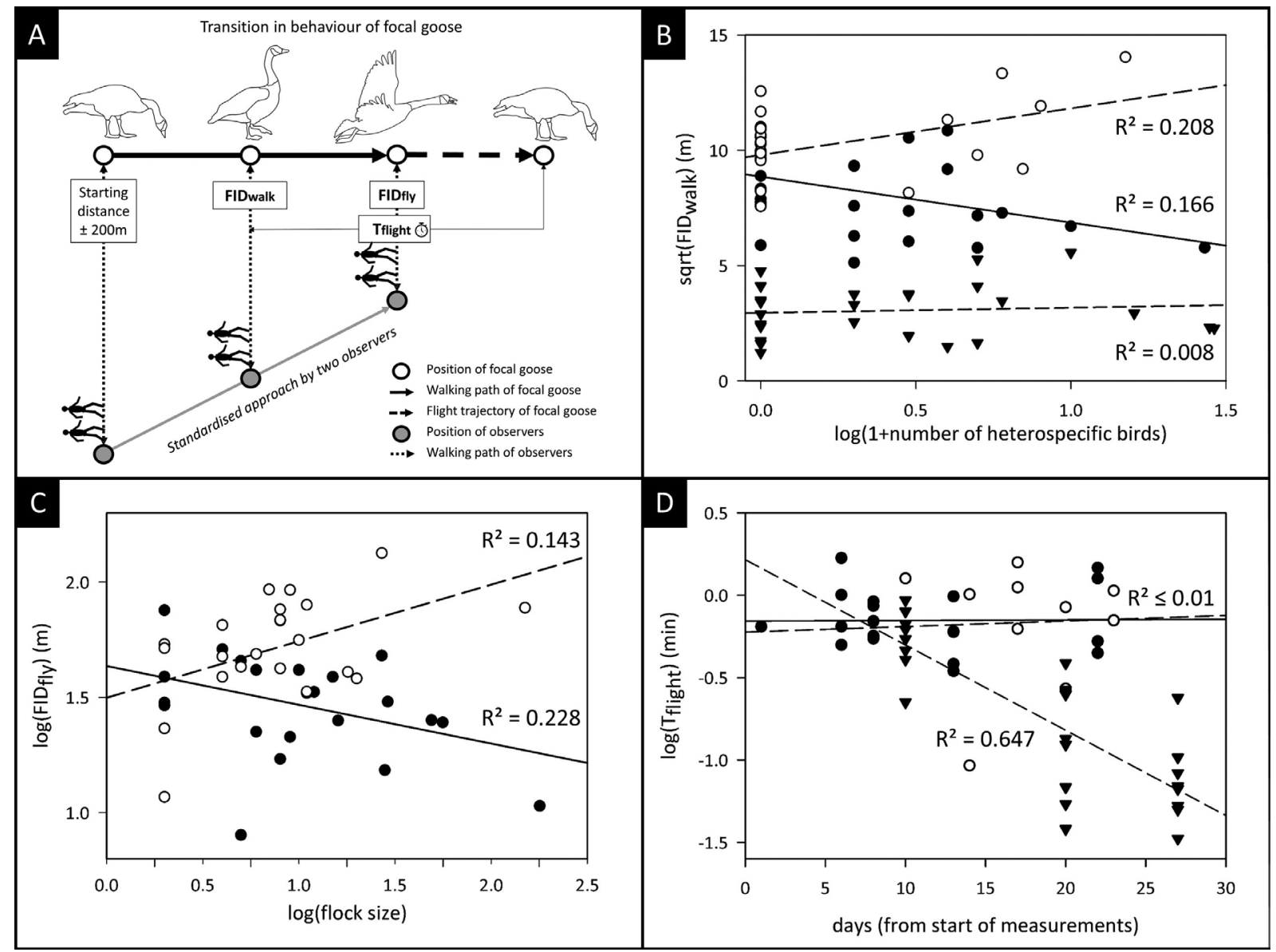

Fig. 1. - Panel A visualises the protocol of escape response measurements. Upon straight approach by two observers from a starting distance of $200 \mathrm{~m}$, the focal individual first started walking away (FID ${ }_{\text {walk }}$ ) and then took flight $\left(\mathrm{FID}_{\mathrm{ff}}\right.$ ) when the observers came closer to the focal goose. To measure both flight distances, the location of the focal goose was identified by small landscape elements such as a patch of tall-standing grasses. The duration of the escape response $\left(\mathrm{T}_{\text {flight }}\right)$ is measured as the total time the focal goose spent moving away from the observers, whether walking or flying, until landing again. Panels B-D present the results for the three escape response metrics, with each symbol representing one flock of birds that was experimentally disturbed. White circles, black circles, and black triangles [different line type] respectively indicate records from Mechels Broek (MB, ○), Bourgoyen-Ossemeersen $(\mathrm{BO}, \bullet)$, and Woluwe Park (WP, $\boldsymbol{\nabla}$ ). Regression lines consist of long dashes, a full line and short dashes for MB, BO and WP, respectively. Panel B shows FID ${ }_{\text {walk }}$ in function of the number of heterospecific individuals in disturbed flocks. In Panel C, FID fly $_{\text {iv }}$ given in function of the total number of individuals in disturbed flocks in the two nature reserves. In WP, geese showed no secondary escape response. Panel D presents the variation in the duration of the escape response, $\mathrm{T}_{\text {fight }}$ in the three locations over the course of the experiment. Observations where the focal individual flew out of sight are omitted from this graph, as the total duration of the escape response could not be measured reliably. 


\section{Material and methods}

\section{Experimental period}

The flight response of Canada Geese was measured between 17 February and 14 March 2016 in two nature reserves, Bourgoyen-Ossemeersen (BO, 220 ha) in Ghent and Mechels Broek (MB, 100 ha) near Mechelen, and an urban park, Woluwe Park (WP, 70 ha) in the Brussels Capital Region. Location visits were alternated as much as possible and were executed in BO on 17, 22, 24, and 29 February and 9 March; in MB on 26 February and 1, 4, 7, and 10 March and in WP on 26 February and 7 and 14 March.

\section{Study area}

Bourgoyen-Ossemeersen (BO) had a paved circular trail for walkers and joggers and a renewed visitor centre at the main entrance of the reserve, separated from an inaccessible core area. Compared to BO, the other nature reserve, Mechels Broek (MB), was located in a more rural environment, had fewer visitor facilities and consisted of unpaved hiking trails with multiple inaccessible areas and a silent zone. In the urban park, the Brussels' Woluwe Park (WP), paved trails were scattered throughout the park, accommodating different types of recreation for Brussels residents. The three locations were selected to incorporate different levels of human accessibility.

In both nature reserves, eggs are punctured and moulting Canada Geese are collectively euthanased every year. In Brussels, including WP, hunting has been forbidden since 1991. Instead, despite prohibitions, waterfowl have been incidentally fed in WP. This, in combination with the fact that there was no harmful experience with humans due to hunting in the past, potentially stimulated a positive perception of close human contact.

Individuals of the three populations did not mix during the selected field work period since Canada Geese show limited dispersal in Belgium: most dispersal occurs within a radius of 20-25 km and their annual movements rarely exceed a 50-km radius (COOLEMAN et al. 2005). During summer the Canada Goose does undertake moult migration to specific wetland areas in Flanders and neighbouring regions, which has increased during the past decade (TANGER \& VOSLAMBER 2011; VAN DAELE et al. 2012). It can therefore not be excluded that some movement took place between the different study areas outside the experimental period.

\section{Escape response measurements}

We distinguished two phases of the flight response: the primary escape response ( $\left.\mathrm{FID}_{\text {walk }}\right)$, which is to start walking away when the disturbance agent approaches, and the secondary response $\left(\mathrm{FID}_{\mathrm{fly}}\right)$, which is to fly away when it has approached even closer. Although generally this distinction is not made for birds, except for some studies (SCHLACHER et al. 2013b; KOCH \& PATON 2014; GENDALL et al. 2015), flying away is energetically more costly and results in the total abandonment of suitable habitat (RIDDINGTON et al. 1996; KOCH \& PATON 2014). The initial walking phase may then be considered as 'buying time' while balancing the necessity of flight with the persistence of the threat (BLUMSTEIN 2010).

For species such as the invasive Canada Goose that are considered less fearful, even aggressive, the difference between these two phases may be an important indicator for sensitivity to disturbance. Also, when geese are moulting in May-July, individuals are only able to walk away from threats.

The field protocol (Fig. 1A) was adapted from Collop et al. (2016). During each location visit, two observers followed walking trails in the same direction until Canada Geese were observed and stopped at least $200 \mathrm{~m}$ away from the individual(s). The Canada Goose closest to the observers was then defined as the focal bird and its exact location was identified by small landscape features, such as a patch of tall-standing grass or mud, with the help of binoculars. The observers walked steadily towards the focal Canada Goose at about $0.5 \mathrm{~ms}^{-1}$ during the entire approach. When the focal individual started walking 
away, a marker was put in the ground as a reference for measuring FID $_{\text {walk }}$. Simultaneously, a timer was started. When the focal goose took flight, the observers stopped to measure FID $_{\text {fly }}$ from their exact location. FID walk and FID fly were measured to the nearest $10 \mathrm{~cm}$ using a $100-\mathrm{m}$ tape measure. The timer was stopped when the focal bird landed again to measure the duration of the escape response $\mathrm{T}_{\text {flight }}$. When the focal bird could not be relocated after three minutes, this was defined as an 'out-of-sight' event. For analysis of $\mathrm{T}_{\text {flight }}$, records where the focal goose flew out of sight were omitted, i.e. respectively four, ten and zero measurements for $\mathrm{BO}, \mathrm{MB}$ and $\mathrm{WP}$.

Prior to each escape response measurement, observers noted additional information on context variables that have been found to affect escape responses. These include weather conditions, the activity of the focal individual and the abundance of other species observed in a $25-\mathrm{m}$ radius of the focal bird. In case the focal individual was part of a single contiguous flock distributed over an area with a larger radius, individuals of the entire flock were counted. The recorded species were Greylag Goose Anser anser (Linnaeus, 1758), Egyptian Goose Alopochen aegyptiaca (Linnaeus, 1766), Common Pochard Aythya ferina (Linnaeus, 1758), Mallard, Grey Heron Ardea cinerea (Linnaeus, 1758; one bird, MB), Barnacle Goose Branta leucopsis (Bechstein, 1803), Magellan Goose Chloephaga picta (Gmelin, 1789), Eurasian Coot Fulica atra (Linnaeus, 1758), Common Moorhen Gallinula chloropus (Linnaeus, 1758), Black-headed Gull Larus ridibundus (Linnaeus, 1766), Eurasian Curlew Numenius arquata (Linnaeus, 1758; one bird, BO), Great Cormorant Phalacrocorax carbo (Linnaeus, 1758; one bird, BO), Common Shelduck Tadorna tadorna (Linnaeus, 1758; one bird, BO), and Northern Lapwing Vanellus vanellus (Linnaeus, 1758; one bird, BO). Species that were observed in the same zone but did not flush simultaneously with the geese flock were excluded (Common Buzzard Buteo buteo (Linnaeus, 1758; one bird, MB), Carrion Crow Corvus corone (Linnaeus, 1758), Common Wood Pigeon Columba palumbus (Linnaeus, 1758), and Eurasian Magpie Pica pica (Linnaeus, 1758)).

In total, 72 escape response measurements were collected in $\mathrm{BO}(N=25)$, the $\mathrm{MB}(N=22)$ and $\mathrm{WP}(N=25)$.

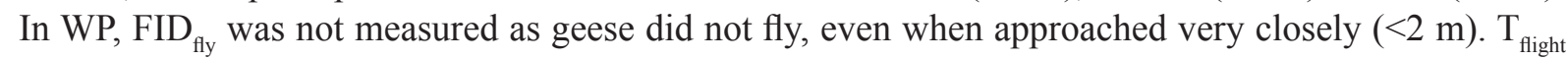
then corresponds to the total time the focal bird spent walking away until resuming its former activity. Birds that showed signs of increased vigilance were not approached for measuring escape responses, as in these cases it is not certain the escape response could be attributed to the observers' approach.

\section{Statistical analysis}

Statistical analyses were performed using R version 3.2.2. (R Core Development Team).

For the three escape response metrics, assumptions of normality and homoscedasticity were checked with Shapiro-Wilk and Levene's tests, respectively. A two-sided Fisher exact test was used to check whether there was a difference between the frequencies at which focal geese flew out of sight in the two nature reserves (BO and $\mathrm{MB}$ ).

To assess whether the different phases of the flight response show similar patterns, i.e., whether early initiation of a primary escape response is also reflected in an early secondary escape response and longer escape duration, the relationship between FID $_{\text {walk, }}$, FID $_{\text {fly }}$ and $\mathrm{T}_{\text {fight }}$ was investigated. The association between $\operatorname{sqrt}\left(\mathrm{FID}_{\text {walk }}\right)$ and $\log \left(\mathrm{FID}_{\mathrm{fly}}\right)$ was examined using Pearson's correlation, while associations between FID $_{\text {walk, }}$, FID $_{\text {fly }}$, and $\mathrm{T}_{\text {flight }}$ had to be tested using non-parametric Spearman correlation tests since residuals were not normally distributed.

Next, the differences in escape behaviour between the three locations were investigated. In a first, more general approach, differences in $\mathrm{FID}_{\text {walk }}$ between $\mathrm{BO}, \mathrm{MB}$ and WP were analysed using oneway ANOVA and Tukey post-hoc tests. A t-test was used to compare differences in FID $_{\text {fly }}$ between $\mathrm{BO}$ and MB (in WP geese did not fly away). FID $_{\text {walk }}$ and FID $_{\text {fly }}$ were respectively square-root and logtransformed for agreement with assumptions of normality and homoscedasticity. To analyse differences between locations for monospecific Canada Geese flocks, Kruskal-Wallis and Wilcoxon rank sum post- 


\section{TABLE 1}

Mean and range of the three escape response measurements for both nature reserves BourgoyenOssemeersen (BO) and Mechels Broek (MB) and the urban park Woluwe Park (WP). Results are listed separately for monospecific Canada Goose flocks, heterospecific flocks (i.e., Canada Geese co-occurring with individuals of at least one other species) and both mono- and heterospecific flocks combined.

\begin{tabular}{ccccccccccc}
\hline & & \multicolumn{3}{c}{ Monospecific flocks } & \multicolumn{4}{c}{ Heterospecific flocks } & \multicolumn{3}{c}{ All measurements } \\
& & Mean (SE) & Range & N & Mean (SE) & Range & N & Mean (SE) & Range & N \\
\hline FID $_{\text {walk }}$ & BO & $83.0(9.8)$ & $34.6-121.4$ & 9 & $61.2(7.5)$ & $26.3-117.9$ & 15 & $69.4(6.2)$ & $26.3-121.4$ & 24 \\
& MB & $100.9(8.0)$ & $57.3-157.8$ & 13 & $127.5(18.4)$ & $66.5-197.2$ & 7 & $110.2(8.5)$ & $57.3-197.2$ & 20 \\
& WP & $9.1(2.2)$ & $1.5-22.7$ & 10 & $11.7(2.2)$ & $2.2-31$ & 15 & $10.6(1.6)$ & $1.5-31.0$ & 25 \\
\hline FID $_{\text {fly }}$ & BO & $37.0(5.4)$ & $17.1-75.5$ & 9 & $31.4(4.3)$ & $8.0-68.0$ & 15 & $33.5(3.3)$ & $8.0-75.5$ & 24 \\
& MB & $50.8(5.6)$ & $11.7-79.7$ & 14 & $72.1(13.4)$ & $38.2-133.7$ & 7 & $57.9(6.0)$ & $11.7-133.7$ & 21 \\
\hline $\mathrm{T}_{\text {flight }}$ & BO & $0.84(0.11)$ & $0.55-1.27$ & 6 & $0.74(0.11)$ & $0.35-1.68$ & 13 & $0.77(0.08)$ & $0.35-1.68$ & 19 \\
& MB & $0.90(0.25)$ & $0.09-1.58$ & 5 & $0.82(0.17)$ & $0.27-1.27$ & 5 & $0.86(0.14)$ & $0.09-1.58$ & 10 \\
& WP & $0.23(0.09)$ & $0.03-0.80$ & 9 & $0.31(0.07)$ & $0.04-0.94$ & 15 & $0.28(0.05)$ & $0.03-0.94$ & 24 \\
\hline
\end{tabular}

hoc tests were applied because of strong heteroscedasticity of FID ${ }_{\text {walk }}$ and FID $_{\text {fly }}$ between locations. In a second part, we performed a more detailed analysis to check which context variables are most important for explaining variation in the different escape response metrics. For this, general linear models (GLMs) were constructed with $\mathrm{FID}_{\text {walk }}, \mathrm{FID}_{\text {fly }}$, and $\mathrm{T}_{\text {flight }}$ as response variables and location (BO, WP, MB), weather conditions (dry/sunny, dry/cloudy and rainy/cloudy) and activity (foraging, grooming, resting) of the focal individual as categorical predictor variables. Continuous predictor variables were day, time of day, Canada Goose flock size, number of individuals from other species in a 25-m radius from the focal individual, and number of people observed on location during the entire site visit. The mean number of visitors ( \pm SE) during the different location visits in Bourgoyen-Ossemeersen was $65 \pm 19$; in Mechels Broek $8 \pm 3$ and in Woluwe Park 59 \pm 7. 'Day' was expressed as the number of days since the first day of the field work, including the days without field work. There was no significant correlation between the number of Canada Geese in the disturbed flock and the number of heterospecific individuals $\left(r_{\mathrm{s}}=0.10\right.$, $P=0.42$ ). Therefore, we can uncouple potential independent effects of the abundance of associated bird species and geese flock size. However, there was a significant correlation between the number of heterospecifics and total flock size $\left(r_{\mathrm{s}}=0.60, P \leq 0.001\right)$ and between the total flock size and the number of Canada Geese $\left(r_{\mathrm{s}}=0.78, P \leq 0.001\right)$.

During backward model selection, we started from a model with all candidate predictor variables and step by step removed the least significant term until we ended up with a model with only significant predictor variables. Non-significant main effects were not removed when they were part of a significant interaction term. The significance of variables was the most important criterion for identifying the best model. We also experimented with forward selection, which resulted in the same final models confirming that consensus models are robust. Response variables $\mathrm{FID}_{\text {walk }}, \mathrm{FID}_{\text {fly }}$ and $\mathrm{T}_{\text {flight }}$ were respectively squareroot-, log- and log-transformed to conform to model assumptions of normality, homoscedasticity and linearity of residuals. For the same reason, both abundance of heterospecific individuals and total flock size (Canada Geese plus other species) were log-transformed.

\section{Results}

Results for the three escape response metrics are summarised in Table 1. The distances at which focal geese could be approached when they initiated walking $\left(\mathrm{FID}_{\text {walk }}\right)$ and flying away $\left(\mathrm{FID}_{\mathrm{fly}}\right)$ were 
TABLE 2

Multiple linear regression models explaining variation in the three escape response metrics. During model construction, variables were stepwise removed from a complete model when the main effect and the interaction between variables were not significant $(\alpha>0.05)$. The main effect was also retained for significant interaction terms. FID $_{\text {walk }}$ and FID $_{\text {fly }}$ represent the distance at which the focal goose could be approached before it initiated walking and flying away, respectively. $\mathrm{T}_{\text {flight }}$ is the total time the focal individual spent walking and flying away. Transformations of variables: ${ }^{\mathrm{a}}=$ square-root; $^{\mathrm{b}}=\log$.

\begin{tabular}{|c|c|c|c|c|c|}
\hline \multirow[t]{5}{*}{ FID $_{\text {walk }}{ }^{a}$} & \multicolumn{5}{|l|}{$\left(F_{5,63}=60.97, R^{2}=0.82, P \leq 0.001\right)$} \\
\hline & Location & 443.16 & 2 & 99.58 & $<0.0001$ \\
\hline & Heterospecific abundance $^{\mathrm{b}}(\beta=-0.87)$ & 9.38 & 1 & 4.21 & $<0.05$ \\
\hline & Location $\times$ heterospecific abundance $\mathrm{e}^{\mathrm{b}}$ & 31.41 & 2 & 7.06 & $<0.01$ \\
\hline & Residuals & 140.18 & 63 & & \\
\hline \multirow[t]{5}{*}{ FID $_{\text {fly }}{ }^{b}$} & $\left(F_{3,41}=7.42, R^{2}=0.30, P \leq 0.001\right)$ & & & & \\
\hline & Location & 0.17 & 1 & 0.71 & 0,4 \\
\hline & Flock size $^{\mathrm{b}}(\beta=-0.16)$ & 0.86 & 1 & 3.54 & 0,07 \\
\hline & Location $\times$ flock size ${ }^{b}$ & 2.03 & 1 & 8.32 & $<0.01$ \\
\hline & Residuals & 10.4 & 1 & & \\
\hline \multirow[t]{5}{*}{$T_{\text {flight }}{ }^{b}$} & $\left(F_{5,44}=27.46, R^{2}=0.73, P \leq 0.001\right)$ & & & & \\
\hline & Location & 1.37 & 2 & 2.17 & 0,13 \\
\hline & Day & 0.001 & 1 & 0.003 & 0,95 \\
\hline & Location $\times$ day & 6.7 & 2 & 10.57 & $<0.001$ \\
\hline & Residuals & 13.95 & 44 & & \\
\hline
\end{tabular}

significantly correlated $(r=0.69, P \leq 0.001)$. The total duration of the escape response $\left(\mathrm{T}_{\text {fligh }}\right)$ was more strongly correlated with $\mathrm{FID}_{\text {walk }}\left(r_{\mathrm{s}}=0.83, P \leq 0.001\right)$ than with $\mathrm{FID}_{\text {fly }}\left(r_{\mathrm{s}}=0.50, P=0.011\right)$.

The distance at which geese initiated the primary escape response FID $_{\text {walk }}$ differed between locations $\left(F_{2,66}=123.19, P \leq 0.001\right)$, with shortest FIDs observed in WP and the largest in MB (Tukey HSD, pairwise BO-MB: $t=4.536$, BO-WP: $t=-10.985$, MB-WP: $t=-15.042$; all $P \leq 0.001$ ).

This pattern was confirmed by general linear regression models (Table 1), where location was retained as a significant variable, in addition to the number of heterospecific individuals and the interaction between location and heterospecific abundance $\left(F_{5,63}=60.97, R^{2}=0.82, P \leq 0.001\right)$. In $\mathrm{MB}, \mathrm{FID}_{\text {walk }}$ increased when more heterospecific birds were present, whereas in BO there was a decreasing trend (Fig. 1B). In WP, the abundance of heterospecific birds did not affect primary escape responses.

The closest distance at which birds could be approached before they flew away $\left(\mathrm{FID}_{\mathrm{fly}}\right)$ was longer in MB than in $\mathrm{BO}\left(t_{31.58}=-3.54, P<0.01\right)$.

Variation in FID $_{\text {fly }}$ was significantly explained by location, total flock size, as well as the interaction between these two variables in the general linear model (Table $2 ; F_{3,41}=7.42, R^{2}=0.30, P \leq 0.001$ ). When flock sizes increased, FID $_{\text {fly }}$ became longer in MB but decreased in BO (Fig. 1C).

For monospecific Canada Geese flocks, FID $_{\text {walk }}$ was similar in the nature reserves $(T=43, P=0.32$; $\left.N_{\mathrm{BO}}=9, N_{\mathrm{MB}}=15\right)$ and smallest in WP $\left(H_{2}=20.513\right.$; with $T=90$ and $T=130$ for comparison with BO and MB, respectively; $N_{\mathrm{wP}}=10$; all $P \leq 0.001$ ). There was no significant difference in FID fly between the reserves $\left(T=33, P=0.062 ; N_{\mathrm{BO}}=9, N_{\mathrm{MB}}=15\right)$. 
The duration of the escape response, $\mathrm{T}_{\text {flight }}$, differed for the three locations $\left(H_{2}=22.06, P \leq 0.001\right)$. Canada Geese spent least time on escape responses in WP compared to BO $(T=398, P \leq 0.001)$ and $\mathrm{MB}$ $(T=211, P \leq 0.001)$. Flight duration did not significantly differ between $\mathrm{BO}$ and $\mathrm{MB}(T=74, P=0.35)$.

Furthermore, the frequency of the focal bird flying out of sight was higher in MB than in BO, respectively $45 \%(10 / 22)$ and $16 \%(4 / 25)(P=0.05)$. In the linear model that described the variation in $\mathrm{T}_{\text {flight }}$ location as well as day and the interaction between these two variables were retained (Table 2). Only in WP was there a decrease in the duration of the escape response towards the end of the experiment (Fig. 1D).

\section{Discussion}

\section{Association between escape response metrics}

We found a strong positive relationship between $\mathrm{FID}_{\text {walk }}$ and $\mathrm{FID}_{\text {fly }}(r=0.69, P \leq 0.001)$, implying that individuals that are more sensitive to disturbance initiate both primary and secondary escape responses sooner. This is consistent with the positive relationship found between alert distances (AD), which indicate the point at which animals display increased vigilance, and FIDs (GUAY et al. 2013; SAMIA et al. 2013). As soon as an animal detects an approaching predator, it needs to continuously monitor the threat. Due to the high costs associated with staying vigilant (BLUMSTEIN 2010), escaping quickly after the threat has been detected allows individuals to maximise the time that can be allocated to foraging, resting or other activities (BLUMSTEIN 2010; SAMIA et al. 2013). Taking flight early, because the cost of escaping is lower than the cost of prolonged vigilance, has been termed the 'flush early to avoid the rush' hypothesis (BLUMSTEIN 2010). It is thus possible that the positive association between walking and flying FIDs is an extension of this hypothesis: not only to initiate flight, but also to intensify the mode of escape quickly.

Moreover, the 'flush early' hypothesis may explain the positive relationship observed between the duration of the escape response and both FIDs: individuals that take flight earlier tend to remove themselves further from the source of disturbance. Especially in larger-bodied species there appears to be a strong positive association between different escape response metrics, which is potentially related to the relative energy efficiency of prolonged flights being higher than for smaller species or to the distribution of alternative habitat and food resources being more limited for large species (TÄTTE et al. 2018).

\section{Effect of flock size and presence of other species on escape responses}

For the walking escape response $\left(\mathrm{FID}_{\text {walk }}\right)$, birds could be approached less closely in $\mathrm{MB}$ if there were more heterospecific birds present. However, this relationship was not found in WP and was slightly negative in $\mathrm{BO}$, with the presence of more heterospecific birds seeming to reduce escape behaviour. For the flying escape response $\left(\mathrm{FID}_{\mathrm{fly}}\right)$, the total number of birds was more important instead, leading to shorter distances at which birds could be approached in BO but longer in MB. It should be noted that relatively few large flocks ( $>50$ individuals) were observed over the course of this study. Similar patterns emerged for both walking and flying away when these records were omitted from the analyses.

A stronger flight reaction (higher FID) in larger flocks, as found in one of our sites (MB), is supported by various studies. Larger flocks of moulting Greylag Geese were more likely to initiate escape in response to various triggers, such as gull alarm calls or helicopters (KAHLERT 2006). Similarly, a positive relationship was described between flock size and flight initiation distance for 17 passerine species (TÄTTE et al. 2018). Furthermore, LAURSEN et al. (2005) discovered that out of the 19 waterbird species that were experimentally disturbed by a single walker, ten species displayed greater escape distances during autumn if flock size increased. During spring, this was observed in only three species, which suggests flock effects may differ greatly between species (LAURSEN et al. 2005). We might assume such species-specific variation in flock effects also had an effect on the observations in this study. Additionally, part of the observed variation in disturbance distances may be attributed to the difference in number of heterospecific individuals between 
study sites. The local species composition is thus important. When more heterospecific birds are present, their effect on the escape response of a flock can also be more pronounced.

The mechanism explaining earlier escape initiation in larger flocks is an increased vigilance and risk avoidance potential, because of the added individual 'scanning' times and the higher probability that a more frequently vigilant individual is present in the flock (MORI et al. 2001; KAHLERT 2006; LEHTONEN \& JAATINEN 2016). However, sometimes individuals decrease their scanning times in larger groups, or the approaching threat is perceived as less harmful, as the risk is diluted for many individuals (GUTZWILLER et al. 1998; YASUÉ 2005). It is not known if the presence of bolder species such as the Canada Goose provides an enhanced feeling of safety for other species in the flock and thereby reduces vigilance in individuals of the other species. Furthermore, larger flocks may be attracted to locations with higher food availability, which they are not likely to abandon quickly (GUTZWILLER et al. 1998). These mechanisms may underlie the more relaxed escape response of larger flocks in BO.

Our model shows that the primary response $\left(\mathrm{FID}_{\text {walk }}\right)$ was influenced by the abundance of heterospecific birds, whereas for the secondary response $\left(\mathrm{FID}_{\mathrm{fly}}\right)$, the model pointed towards a higher importance of the total number of birds in the flock. Both predictors, however, are correlated $\left(r_{s}=0.60, P \leq 0.001\right)$, hence we cannot pinpoint whether heterospecifics indeed matter more for the escape response than the total number of birds in a flock. In both cases, the behavioural shift of a few vigilant animals can stimulate flight reactions that propagate as an 'escape wave', even more efficiently so in larger flocks (BEAUCHAMP 2012; HERBERT-READ et al. 2015). Also, different dynamics may exist in the transmission of the escape signal. For instance, this process may occur faster for more prominent movements, for signals that are more easily recognised by closely related or co-occurring species, or when additional signals are involved such as alarm calls (BOUJJA-MiLJOUR et al. 2017).

\section{Differences in disturbance distances between sites}

Comparing nature reserves, both FID $_{\text {walk }}$ and FID $_{\text {fly }}$ were shorter in Bourgoyen-Ossemeersen (BO) than in Mechels Broek (MB). As often observed in urban populations (LIN et al. 2012; GEFFROY et al. 2015; VINCZE et al. 2016), Canada Geese in the Woluwe Park (WP) could be approached most closely and even did not fly away. The greater response to human disturbance in the nature reserves compared to the urban park was not only related to the presence of other species, as monospecific flocks of Canada Geese also display larger FID in the nature reserves $(T=90$ and $T=130$ for comparison with BO and MB respectively, both $P \leq 0.001$ ). This implies that there is a general pattern of Canada Goose populations being more sensitive to disturbance in the nature reserves and more tolerant in the park. It should be noted that birds in WP may be more familiar with the exact type of disturbance in this experiment than geese from $\mathrm{BO}$ and $\mathrm{MB}$, because visitors can walk more freely in WP. In comparison, a direct approach by humans on foot, off the designated paths, may be unusual and hence more easily interpreted a potential threat by birds in BO and MB. Possibly the larger $\mathrm{FID}_{\text {walk }}$, and to lesser extent $\mathrm{FID}_{\text {fly }}$, in one of the nature reserves (MB) compared to the other (BO) could be linked to the lower human accessibility and different spatial planning in $\mathrm{MB}$ and the proximity of a larger city and the presence of more variable types of human recreation in $\mathrm{BO}$, but this is speculative. More information on local recreation pressure, food and shelter availability and proximity of alternative suitable habitats is needed to address the drivers for variation in escape behaviour in these sites.

\section{Difference in escape response duration between sites}

In contrast to the patterns observed for the distance metrics (FID), we found no associations between the total duration of the escape response and group size- or composition- related variables. Rather surprisingly, because we did not expect to find temporal patterns within the relatively restricted time period of the experiment, the day at which the measurement was executed was retained as a significant term in interaction with location. This reflects the decreasing trend in $\mathrm{T}_{\text {flight }}$ throughout the study period in WP and the lack of a clear trend in the nature reserves. This is probably because only a relatively low 
number of measurements were retained after omitting the records where the focal bird flew beyond our field of vision and because measurements in WP were executed on just three different days. There is thus no clear evidence for effects of behavioural changes before the breeding season on flight responses. Moreover, there are hardly any suitable nesting locations available in WP that are inaccessible by humans, so it is unlikely many Canada geese prepare for or attempt breeding in WP.

\section{Conclusion}

Invasive species such as the Canada Goose can be a valuable model to analyse how local context alters escape behaviour. These model species may improve our understanding of how bolder, more disturbance-tolerant birds can influence the flight reaction of more sensitive individuals, and vice versa. Populations may adjust their escape strategies based on locally experienced conditions and interactions with local species assemblages. Therefore, generalisations that are currently made in buffer design may lead to severe overestimations of the tolerance of birds to human disturbance in multispecies flocks when extrapolating thresholds between different sites. For instance, in this study, the largest distance at which geese were approached when they initiated the escape, measured in one of the nature reserves, is approximately 130 times larger than the smallest distance, measured in the urban park. Nature and recreation objectives are indeed subject to different trade-offs in protected areas and parks. In some areas, a spatial planning based on a safer, 'maximum FID' distance can be necessary to protect sensitive populations, whereas such solutions may not be realistic or desirable in urban parks.

In the case of pest species, the efficiency of control plans may benefit from a better insight into the distance at which individual birds or flocks can be approached, and into which context this distance is the smallest. For instance, understanding how flock interactions affect escape behaviour could allow managers to target pest species while limiting the impact on non-target or protected species.

Also, since the three escape response metrics are considered to have different biological implications and are found to be associated with different context variables in this study, we would recommend measuring several indicators to assess the local drivers of escape behaviour.

\section{Acknowledgements}

We thank B. De Muynck of the Environmental Office of Ghent, T. Van den Broeck, management team coordinator of Natuurpunt Mechelen, and O. Beck, species policy officer at the department of renewables and environment (BIM) in Brussels, for granting us permission to execute the field work in the Bourgoyen-Ossemeersen, the Mechels Broek and the Woluwe Park, respectively. They also shared valuable information about the sites and the local Canada Goose populations. L. Abts, I. Derden, C. Retsin, M. Vangyseghem and J. Vansynghel provided field assistance. ED is supported by a PhD fellowship 11ZH516N from the Research Foundation - Flanders (FWO). The authors would like to thank two anonymous reviewers for their constructive comments on a previous version of this manuscript.

\section{References}

Arlettaz R., Nusslé S., Baltic M., Vogel P., Palme R., Jenni-Eiermann S., Patthey P. \& Genoud M. (2015). Disturbance of wildlife by outdoor winter recreation: allostatic stress response and altered activityenergy budgets. Ecological Applications 25: 1197-1212. https://doi.org/10.1890/14-1141.1

Beale C.M. \& Monaghan P. (2004). Human disturbance: people as predation-free predators? Journal of Applied Ecology 41: 335-343. https://doi.org/10.1111/j.0021-8901.2004.00900.x

BEAUCHAMP G. (2012). Flock size and density influence speed of escape waves in Semipalmated Sandpipers. Animal Behaviour 83: 1125-1129. https://doi.org/10.1016/j.anbehav.2012.02.004 
BéChet A., Giroux J.-F. \& GAUthier G. (2004). The effects of spring disturbance on behaviour, habitat use and energy of spring staging Snow Geese. Journal of Applied Ecology 41: 689-700. https://doi.org/10.1111/j.0021-8901.2004.00928.x

Bejder L., SAmuels A., Whitehead H., FinN H. \& Allen S. (2009). Impact assessment research: use and misuse of habituation, sensitisation and tolerance in describing wildlife responses to anthropogenic stimuli. Marine Ecology Progress Series 395: 177-185. https://doi.org/10.3354/meps07979

BLUMSTEIN D.T. (2010). Flush early and avoid the rush: a general rule of antipredator behaviour? Behavioral Ecology 21: 440-442. https://doi.org/10.1093/beheco/arq030

BoujJa-Miljour H., Leighton P.A. \& Beauchamp G. (2017). Spread of false alarms in foraging flocks of house sparrows. Ethology 123: 526-531. https://doi.org/10.1111/eth.12622

Chapple D.G., Simmonds S.M. \& Wong B.B.M. (2012). Can behavioral and personality traits influence the success of unintentional species introductions? Trends in Ecology and Evolution 27: 57-64. https://doi.org/10.1016/j.tree.2011.09.010

CHATwin T.A., JOY R. \& BURGER A.E. (2013). Set-back distances to protect nesting and roosting seabirds off Vancouver Island from boat disturbance. Waterbirds 36: 43-52. https://doi.org/10.1675/063.036.0108

Collins-Kreiner N., Malkinson D., Labinger Z. \& Shtainvarz R. (2013). Are birders good for birds? Bird conservation through tourism management in the Hula Valley, Israel. Tourism Management 38: 31-42. https://doi.org/10.1016/j.tourman.2013.01.009

Collop C., Stillman R.A., Garbutt A., Yates M.G., Rispin E. \& Yates T. (2016). Variability in the area, energy and time cost of wintering waders responding to disturbance. Ibis 158: 711-725. https://doi.org/10.1111/ibi.12399

Cooleman S., Anselin A., Beck O., KuiJKen E. \& Lens L. (2005). Verplaatsingen en mortaliteit van Canadese Ganzen Branta canadensis in Vlaanderen. Natuur Oriolus 71 (attachment): 152-160.

Cote J., Fogarty S., Weinersmith K., Brodin T. \& Sin A. (2010). Personality traits and dispersal tendency in the invasive mosquitofish (Gambusia affinis). Proceedings of the Royal Society B 277: 1571-1579. https://doi.org/10.1098/rspb.2009.2128

DoOley J.L., SANDERS T.A. \& DoHERTY P.F. (2010). Mallard response to experimental walk-in and shooting disturbance. Journal of Wildlife Management 74 (8): 1815-1824.

https://doi.org/10.2193/2009-284

DoraK B.E., Ward M.P., EichHOlz M.W., WashbuRn B.E., LyONS T.P. \& Hagy H.M. (2017). Survival and habitat selection of Canada Geese during autumn and winter in metropolitan Chicago, USA. The Condor 119: 787-799. https://doi.org/10.1650/CONDOR-16-234.1

Gefrroy B., Samia D.S.M., Bessa E. \& Blumstein D.T. (2015). How nature-based tourism might increase prey vulnerability to predators. Trends in Ecology and Evolution 30: 755-765.

https://doi.org/10.1016/j.tree.2015.09.010

Gendall J., Lill A. \& BeCKMAN J. (2015). Tolerance of disturbance by humans in long-time resident and recent colonist urban doves. Avian Research 6: 1-8. https://doi.org/10.1186/s40657-015-0018-x

Glover H.K., Weston M.A., Maguire G.S., Miller K.K. \& Christie B.A. (2011). Towards ecologically meaningful and socially acceptable buffers: response distances of shorebirds in Victoria, Australia, to human disturbance. Landscape and Urban Planning 103: 326-334.

https://doi.org/10.1016/j.landurbplan.2011.08.006

Guay P.-J., Mcleod E.M., Cross R., Formby A.J., Maldonado S.P., Stafford-Bell R.E., StJAMES-Turner Z.N., Robinson R.W., Mulder R.A. \& Weston M.A. (2013). Observer effects occur when estimating alert but not flight-initiation distances. Wildlife Research 40: 289-293. https://doi.org/10.1071/WR13013 
Gutzwiller K.J., Marcum H.A., Harvey H.B., Roth J.D. \& Anderson S.H. (1998). Bird tolerance to human intrusion in Wyoming montane forests. The Condor 100: 519-527. https://doi.org/10.2307/1369718

Hagy H.M., Horath M.M., Yetter A.P., Hine C.S. \& Smith R.V. (2017). Evaluating tradeoffs between sanctuary for migrating waterbirds and recreational opportunities in a restored wetland complex. Hydrobiologia 804: 103-118. https://doi.org/10.1007/s10750-016-2711-0

Herbert-Read J.E., BuHL J., Hu F., WARD A.J.W. \& Sumpter D.J.T. (2015). Initiation and spread of escape waves within animal groups. Royal Society Open Science 2: 140355.

https://doi.org/10.1098/rsos.140355

KAHLERT J. (2006). Factors affecting the escape behaviour in moulting Greylag Geese Anser anser. Journal of Ornithology 147: 569-577. https://doi.org/10.1007/s10336-006-0081-5

Koch S.L. \& PATON P.W.C. (2014). Assessing anthropogenic disturbances to develop buffer zones for shorebirds using a stopover site. Journal of Wildlife Management 78 (1): 58-67.

https://doi.org/10.1002/jwmg.631

LAURSEN K., KAHLERT J. \& FRIKKE J. (2005). Factors affecting escape distances of staging waterbirds. Wildlife Biology 11: 13-19. https://doi.org/10.2981/0909-6396(2005)11[13:FAEDOS]2.0.CO;2

Laursen K., Møller A.P. \& Holm T.E. (2016). Dynamic group size and displacement as avoidance strategies by eiders in response to hunting. Wildlife Biology 22: 174-181.

https://doi.org/10.2981/wlb.00197

LEHTONEN J. \& JAATINEN K. (2016). Safety in numbers: the dilution effect and other drivers of group life in the face of danger. Behavioural Ecology and Sociobiology 70: 449-458.

https://doi.org/10.1007/s00265-016-2075-5

Lin T., Coppack T., Lin Q.-X., Kulemeyer C., Schmidt A., Behm H. \& Luo T. (2012). Does avian flight initiation distance indicate tolerance towards human disturbance? Ecological Indicators 15: 3035. https://doi.org/10.1016/j.ecolind.2011.09.018

LODGE D.M. (1993). Biological invasions: lessons for ecology. Trends in Ecology and Evolution 8: 133-136. https://doi.org/10.1016/0169-5347(93)90025-K

Mori Y., SodHi N.S., KAWANiSHI S. \& YAMAgiSHI S. (2001). The effect of human disturbance and flock composition on the flight distances of waterfowl species. Journal of Ethology 19: 115-119. https://doi.org/10.1007/s101640170007

Riddington R., HASSAll M., LANE S.J., TURNER P.A. \& WALters R. (1996). The impact of disturbance on the behaviour and energy budgets of Brent Geese Branta b. bernicla. Bird Study 43: 269-279. https://doi.org/10.1080/00063659609461019

SAMiA D.S.M., NOMURA F. \& BlumSTEIN D.T. (2013). Do animals generally flush early and avoid the rush? A meta-analysis. Biology Letters 9: 20130016. https://doi.org/10.1098/rsbl.2013.0016

SChlACHER T.A., NiELSEN T. \& WeStON M.A. (2013a). Human recreation alters behaviour profiles of non-breeding birds on open-coast sandy shores. Estuarine, Coastal and Shelf Science 118: 31-42. https://doi.org/10.1016/j.ecss.2012.12.016

Schlacher T.A., Weston M.A., LynN D. \& ConNolly R.M. (2013b). Setback distances as a conservation tool in wildlife-human interactions: testing their efficacy for birds affected by vehicles on open-coast sandy beaches. PLoS ONE 8: e71200. https://doi.org/10.1371/journal.pone.0071200

Sol D., TIMMERMAnS S. \& LeFeBVRE L. (2002). Behavioural flexibility and invasion success in birds. Animal Behaviour 63: 495-502. https://doi.org/10.1006/anbe.2001.1953

Sol D., LAPIEDRA O. \& GONZÁLEZ-LaGos C. (2013). Behavioural adjustments for life in the city. Animal Behaviour 85: 1101-1112. https://doi.org/10.1016/j.anbehav.2013.01.023 
SRIDHAR H. \& SHANKER K. (2014). Using intra-flock association patterns to understand why birds participate in mixed-species foraging flocks in terrestrial habitats. Behavioural Ecology and Sociobiology 68: 185-196. https://doi.org/10.1007/s00265-013-1633-3

TANGer D. \& Voslamber B. (2011). Ruitrek van Canadese ganzen over Nederland in relatie tot de veiligheid rond vliegvelden. De Grauwe Gors 2011-3: 135-137.

TÄTte K., MøLleR A.P. \& MÄND R. (2018). Towards an integrated view of escape decision in birds: relation between flight initiation distance and distance fled. Animal Behaviour 136: 75-86. https://doi.org/10.1016/j.anbehav.2017.12.008

Uchida K., Suzuki K., Shimamoto T., Yanagawa H. \& Koizumi I. (2016). Seasonal variation of flight initiation distance in Eurasian Red Squirrels in urban versus rural habitat. Journal of Zoology 298: 225-231. https://doi.org/10.1111/jzo.12306

Van Daele P., Adriaens T., Devisscher S., Huysentruyt F., Voslamber B., De Boer V., DeVos K. \& CASAER J. (2012). Beheer van zomerganzen in Vlaanderen en Zeeuws-Vlaanderen. Research Institute Nature and Forest.

Vincze E., PApp S., Preiszner B., Seress G., Bókony V. \& Liker A. (2016). Habituation to human disturbance is faster in urban that rural House Sparrows. Behavioral Ecology 27 (5): 1304-1313. https://doi.org/10.1093/beheco/arw047

WANG Z., Li Z., BEAUCHAMP G. \& JIANG Z. (2011). Flock size and human disturbance affect vigilance of endangered Red-Crowned Cranes (Grus japonensis). Biological Conservation 144: 101-105. https://doi.org/10.1016/j.biocon.2010.06.025

YASUÉ M. (2005). The effects of human presence, flock size and prey density on shorebird foraging rates. Journal of Ethology 23: 199-204. https://doi.org/10.1007/s10164-005-0152-8

Manuscript received: 12 January 2018

Manuscript accepted: 31 July 2018

Published on: 7 September 2018

Branch editor: Stuart Halse 